\title{
Critical periods of adaptation to oncogenic environmental factors at the stages of ontogenesis
}

\author{
Sergey K. Pinaev ${ }^{1, *}$, Alexey Ya. Chizhov ${ }^{2}$, and Olga G. Pinaeva ${ }^{1}$ \\ ${ }^{1}$ Far Eastern State Medical University, Khabarovsk, Russia \\ ${ }^{2}$ Medical ecological center "Mountain air XXI century", Moscow, Russia
}

\begin{abstract}
The study of fluctuations in the incidence of neoplasms in children give us a possibility to identify critical periods of adaptation to oncogenic environmental factors at the stages of ontogenesis. This provides additional opportunities for the development of prevention measures of childhood malignant neoplasms.
\end{abstract}

The role of environmental factors (EF) in the development of malignant neoplasms (MN) is generally recognized [1]. For the prevention of ecologically caused neoplasias, it is necessary to clarify the critical periods of adaptation (CPA) to oncogenic EF at the stages of ontogenesis.

Anthropotechnogenic EF is usually characterized by monotonic tendencies, while natural factors more frequently have significant annual fluctuations. In this regard, the initial study of natural potentially oncogenic effects seems promising. These data can form the basis for identifying similar EFs caused by human activity.

In our approach, we proceed from the assumption that the so-called "spontaneous" fluctuations in the incidence of neoplasms can be caused by EF. The study of the incidence of neoplasms in cohorts of young children (YC) 0-4 years old is a very sensitive indicator of the effect of EF due to the prenatal origin of the majority of these pathologies and the short period between oncogenic exposure and the onset of a tumor [2]. A specific feature of our approach is a simultaneous study of the incidence of benign and malignant neoplasms in YC cohorts, that makes possible to identify the CPA for specific tissues.

According to our concept, CPA for certain tissues and systems appear when the critical period of ontogenesis is superimposed on an ecologically determined critical period, that is characterized by the excess of the EF resistance threshold for these tissues (Fig. 1).

Determination of the lag between the peak values of EF and an increase in the incidence of neoplasms in the YC cohorts let us identify CPA both at the preconceptional, and at the antenatal and postnatal stages of ontogenesis.

We reported earlier on the revealed relations between solar activity and smoke from forest fires with a number of benign and $\mathrm{MN}$ in the cohorts of the YC in the Khabarovsk Territory $[3,4]$. Preconception CPA for solar activity with a lag of 3 years before the birth of children was revealed for hemangiomas, as well as for benign tumors of soft tissues,

*Corresponding author: pinaev@mail.ru 
papillomas of the skin and mucous membranes. CPA to solar activity in non-Hodgkin's lymphomas (NHL) fell on the antenatal period, in soft tissue sarcomas it coincided with the year of birth, while for leukemia and Wilms' tumor it was 3 years old. CPA for smoke had a lag of 2 years before the birth of children with lymphangiomas, Hodgkin lymphoma and leukemia, with retinoblastoma and neuroblastoma, CPA fell on the year of birth, and for teratomas - at the age of 1 year. Tumors of the central nervous system were associated with CPA to forest fire smoke at the age of 1 year, and in hemangiomas, CPA was connected with this factor at the age of 3 years.

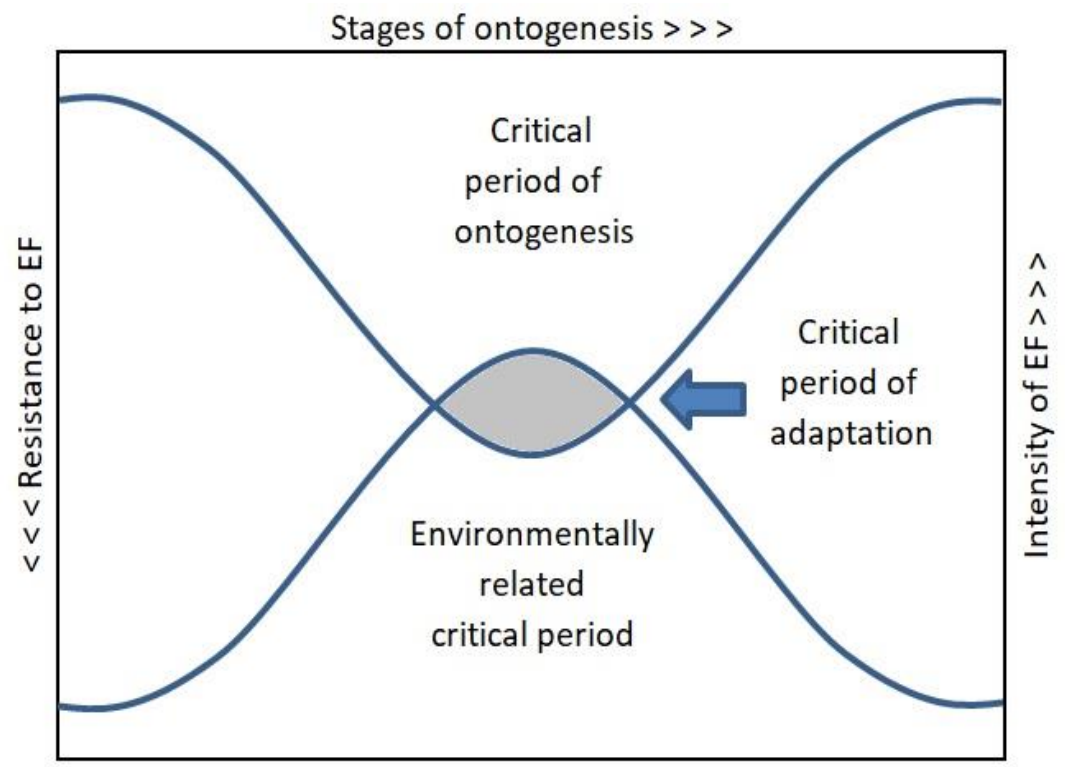

Time, years $>>>$

Fig. 1. Scheme of the emergence of the critical period of adaptation when the critical period of ontogeny is superimposed on the ecologically determined critical period.

In this study, we expanded the age, territorial and time scales by conducting a study of the CPA to solar activity in leukemia and NHL in the child population of Russia (0-14 years old) for 23 years (1997-2019). The data of the MN incidence were taken from the official reports of the Moscow Research and Development Institute. P.A. Herzen [5, 6, 7], data on solar activity (average annual Wolf number) were obtained from the website of the Royal Observatory of Belgium [8]. The generated time series were analyzed by Pearson correlation using the IBM SPSS Statistics 23 package in 10 iterations using the time lag $(0$, $-1,-2,-3,-4,-5,-6,-7,-8,-9$ years) in relation to the year of registration of the MN.

When processing time series with a length of 23 years, no significant connections between the incidence of leukemia and solar activity was found in any iteration. Since, averagely, every 11 years there is a change in the magnetic poles of the Sun and a significant change in its activity, for further research we divided the time series into two segments (1997 - 2008 and 2009-2019), corresponding to 23 and 24 solar cycles, respectively [9].

The investigation of the time series of childhood leukemia incidence in $1997-2008$ showed a strong highly reliable link with the activity of the Sun $(r=0.749, p=0.005)$ with a lag of 3 years. The incidence of leukemia in 2009 - 2019 turned out to be associated with solar activity with a lag of 2 years $(r=0.668, \mathrm{p}=0.025)$. 
The study of children NHL incidence in Russia in 1997 - 2019 demonstrated a significant correlation with the Wolf number $(r=0.483, p=0.020)$ with a lag of 5 years (Fig. 2$)$.

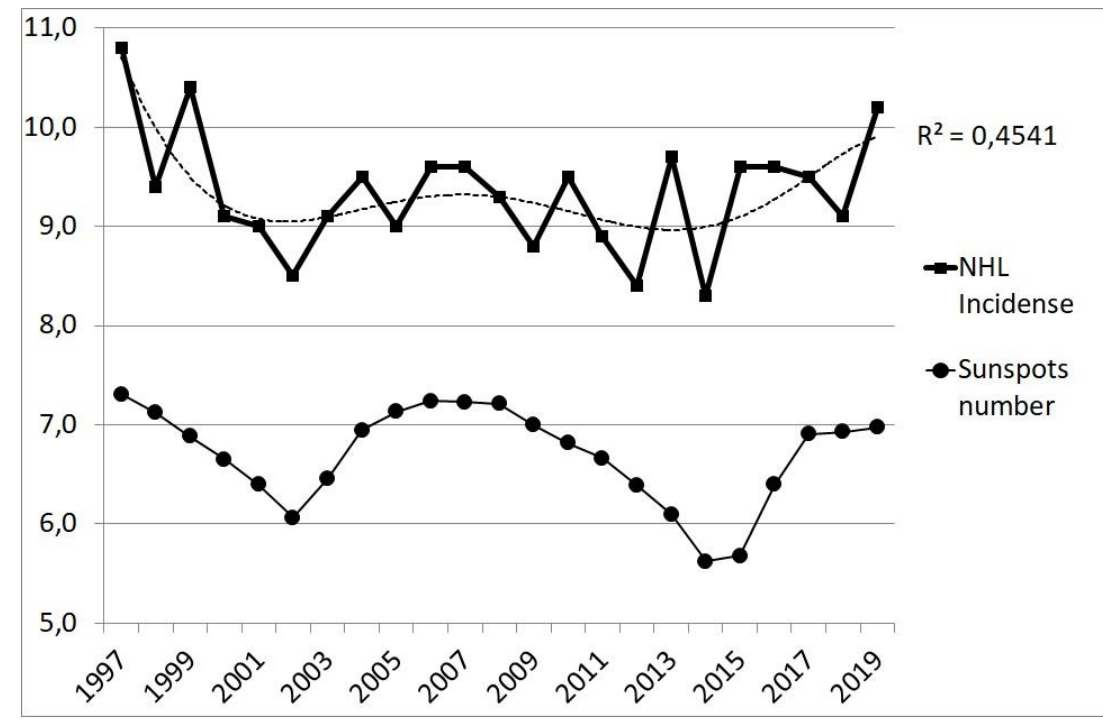

Fig. 2. Trends of solar activity ( $\log 10$ Sunspots number +5$)$ and childhood NHL incidence in Russia (per 106, lag 5 years).

After dividing the time series, the connection between solar activity and the NHL incidence in 1997 - 2008 with a lag of 7 years, it reached a significant level $(r=0.669, p=$ 0.017), having weakened in 2009 - 2019 with a decrease in the lag to 4 years while maintaining reliability tendency $(\mathrm{r}=0.522, \mathrm{p}=0.099)$.

The average age of diagnoses of both leukemia and NHL in children is 6 years [10]. To calculate the CPA to solar activity in leukemia, we subtract the lag (2-3 years) from the average age of diagnosis and we found out that the CPA to this EF fell on the age of 3-4 years. Similarly, the CPA to the activity of the Sun during NHL was in the range from $(-1)$, that was one year before birth, to 2 years. This is quite close to the CPA parameters obtained by the working with the YC cohorts.

Thus, the analysis of fluctuations in the incidence of different forms of $\mathrm{MN}$ both in the $\mathrm{YC}$ cohorts and in the childhood population as a whole allow to identify CPA of certain tissues to EF at the stages of ontogenesis, helping to develop more effective measures to prevent this very painful for the society pathology.

\section{References}

1. N.A. Agadzhanyan, A. Ya. Chischov, T.A. Kim, Human Ecology, 4, 8-11 (2003)

2. A. Bleyer, R. Barr, L. Ries, J. Whelan, A. Ferrari, (Eds) Cancer in Adolescents and Young Adults: Pediatric Oncology (Springer International Publishing AG, 2017)

3. S.K. Pinaev, RAD Conf. Proc, 4, 69-71 (2020)

4. S.K. Pinaev, A.Ya. Chizhov, Radiation and risk, 29(1), 68-78 (2020)

5. Eds. V.I. Chissov, V.V. Starinskiy, G.V. Petrova, P.Herzen, Malignant neoplasms in Russia in 2007 (morbidity and mortality), (Moscow Oncology Research Institute, 2009) (In Russian) 
6. A.D. Kaprin, V.V. Starinskiy, G.V. Petrova, P.Herzen (Eds.), Malignant neoplasms in Russia in 2017 (morbidity and mortality) (Moscow Oncology Research Institute, 2018) (In Russian)

7. A.D. Kaprin, V.V. Starinskiy, A.O. Shakhzadova, P.Herzen (Eds.), Malignant neoplasms in Russia in 2019 (morbidity and mortality) (Moscow Oncology Research Institute, 2020) (In Russian)

8. SILSO data/image (Royal Observatory of Belgium, Brussels, 2021)

9. V.N. Ishkov, Space Research, 58(6), 471-478 (2020) (In Russian)

10. O.G. Zheludkova, V.G. Polyakov, M.Yu. Rykov, N.A. Susuleva, I.A. Turabov, Clinical manifestations of cancer in children: practical recommendations (Mikhail Fursov Printing House, S.-Peterbourg, 2017) (In Russian) 